\title{
Flow versus pressure control of pumps in mobile hydraulic systems
}

\author{
Mikael Axin, Björn Eriksson and Petter Krus
}

\section{Linköping University Post Print}

\section{Tweet}

N.B.: When citing this work, cite the original article.

Original Publication:

Mikael Axin, Björn Eriksson and Petter Krus, Flow versus pressure control of pumps in mobile hydraulic systems, 2014, Proceedings of the Institution of mechanical engineers. Part I, journal of systems and control engineering, (228), 4, 245-256.

http://dx.doi.org/10.1177/0959651813512820

Copyright: SAGE Publications (UK and US) http://www.uk.sagepub.com/home.nav

Postprint available at: Linköping University Electronic Press

http://urn.kb.se/resolve?urn=urn:nbn:se:liu:diva-105796 


\title{
Flow vs. pressure control of pumps in mobile hydraulic systems
}

\author{
Mikael Axin, Björn Eriksson and Petter Krus
}

\begin{abstract}
This work studies an innovate working hydraulic system design for mobile applications, referred to as flow control. The fundamental difference compared to load sensing systems is that the pump is controlled based on the operator's command signals rather than feedback signals from the loads. This control approach enables higher energy efficiency since the pressure difference between pump and load is given by the system resistance rather than a prescribed pump pressure margin. Furthermore, load sensing systems suffer from poor dynamic characteristics since the pump is operated in a closed loop control mode. This might result in an oscillatory behaviour. Flow control systems have no stability issues attached to the load pressure feedback since there is none. This allows the pump to be designed to meet the response requirements without considering system stability. Pressure compensators are key components in flow control systems. This study addresses the flow matching problem which occurs when using traditional compensators in combination with a flow controlled pump. Flow sharing pressure compensators solve this problem since the pump flow will be distributed between all active functions. Simulation results and measurements on a wheel loader application demonstrate the energy saving potentials and the dynamic improvements for the flow control system.
\end{abstract}

\author{
Keywords \\ Hydraulics, flow control, load-sensing, mobile systems, energy efficiency, dynamic characteristics, compensators
}

Date received: 28 August 2013

\section{Introduction}

Mobile hydraulic applications distinguish themselves from other hydraulic applications, such as industrial hydraulics, because the pressure and flow demand varies greatly over time and between different functions. Unlike other hydraulic applications, several functions are often supplied by one single pump. This means that the total installed power on the actuator side is generally considerably higher than the installed pump power. This is possible because the actuators almost never require their maximum power at the same time. The need for only one system pump makes the hydraulic system compact and costeffective.

Other important properties of mobile hydraulic systems are energy efficiency and controllability characteristics. For these reasons, development has been pushed towards load sensing systems, which is state-of-the-art in industry today. Load sensing systems often use a hydromechanical pump controller. However, the development of electro-hydraulic pump controllers opens up new possibilities in terms of innovative pump control strategies.

Instead of using feedback signals from the loads, it is possible to control the pump displacement setting based on the operator's command signals when using an electro- hydraulic pump controller. The pump displacement setting is then controlled according to the sum of all requested load flows. This control approach enables higher energy efficiency since the pressure difference between pump and load is given by the system resistance rather than a prescribed pump pressure margin. Furthermore, it also improves the dynamic characteristics since the pump is no longer operated in a closed loop control mode.

In the literature, different researchers have used different names for systems where the pump displacement setting is controlled according to the sum of all requested load flows. Initial considerations regarding this pump control strategy were patented by Stenlund [1] in the late 1980s under the name "Electrohydraulic guide system". Similar ideas were published by Zähe [2] in 1993 under the name "Summenstromreglerung", which roughly

Division of Fluid and Mechatronic Systems, Department of Management and Engineering, Linköping University, Sweden

Corresponding author:

Mikael Axin, Linköping University, SE-581 83, Linköping

Email: mikael.axin@liu.se 
means "Aggregate flow control". However, suitable electro-hydraulic components were not available until several years later. In 2004, research intensified [3] [4] [5]. Jongebloed et al. [3] used pressure sensors at all load ports for the valve control, calling the system "LCS Load-Control-System". Djurovic [6] studied a system design with traditional pressure compensators, which requires the pump flow to be matched against the sum of all load flows, sometimes referred to as the "flow matching problem" [7]. Consequently, he used the notation "EFM - Electrohydraulic Flow Matching", which is a proprietary Bosch Rexroth brand name [8]. Fedde and Harms [9] studied a similar system design and used the notation "Flow Demand System". They used a bleedoff valve to deal with the flow matching and studied the pros and cons of overflow and underflow from the pump. Finzel [10] continued Djurovic work and introduced flow sharing compensators. Such compensators distribute the entire pump flow relative to the individual valve openings, thus eliminating the flow matching problem. Axin et al. [11] studied the pros and cons of different types of compensator design in combination with a flow controlled pump, including the dynamic properties, calling the system "Flow control system". In later publications, Scherer et al. [12] proposed a solution to deal with a cylinder reaching its end stop and refer to the circuit as "FlowOn-Demand system".

This study gives an overview of the pros and cons of controlling the pump according to the sum of all requested load flows. Pressure compensators, energy efficiency and dynamic characteristics are discussed and compared to conventional load sensing systems. Simulation and experimental results confirming the theoretical expectations are also presented.

\section{Mobile working hydraulic systems}

Fluid power systems have been used successfully in mobile machines for several decades. Because of the machines' versatility, different hydraulic systems have been developed for different applications. Important properties of hydraulic systems are energy efficiency, dynamic characteristics, controllability and system complexity. However, the order of importance of these properties varies for different applications. This section gives an overview of the most commonly used working hydraulic systems of today. It also presents some innovative system designs that have not yet been commercialized but are attracting considerable attention both in industry as well as academia. Energy efficiency, dynamic characteristics, controllability and system complexity are discussed and compared.

Today, most hydraulic systems in mobile machines are operated with open-centre valves and fixed displacement pumps, see figure 1a. Such systems can be considered to be relatively simple, robust and cost-effective, but also often inefficient. These systems suffer from load interference, which means that the pressure level at one load can heavily influence the velocity of another actuator. Furthermore, the flow rate is not only dependent on spool position, but also on load pressure, often referred to as load dependency. From a controllability point of view, this is often considered a drawback, but skilled operators can actually use this information feedback from the system to their advantage. From a dynamic point of view load dependency is a desired property. It gives the system a naturally high damping, which means that the system is less prone to oscillations. To obtain damping from a valve, the flow has to increase when the pressure drop across the valve increases and vice versa. Damping is a preferred property when handling large inertia loads, for example the swing function of a mobile crane.

Constant pressure systems improve the controllability compared to open-centre systems since it has no load interference issues. Other characteristics, such as efficiency and dynamics, are similar to open-centre systems and the complexity is slightly higher, mainly because constant pressure systems often use a pressure controlled variable displacement pump. It is, however, possible to increase the energy efficiency of constant pressure systems by, for example, using secondary control [13] or introducing an intermediate pressure line [14].

Load sensing systems improve the energy efficiency compared to open-centre and constant pressure systems by continuously adapting their pressure just above the highest load. A pressure difference, usually around 2030 bar, between pump and load is necessary to overcome losses in hoses and valves. This pressure margin is often set substantially higher than necessary to ensure it is high enough at all operational points. A load sensing valve is often equipped with a pressure compensator which controls the pressure drop across the directional valve, see figure 1b. Different loads can thereby be operated almost without load interference and load dependency, giving excellent controllability properties. An early review of load sensing systems was made by Andersson in [15].

One weakness of load sensing systems using pressure compensated valves is the hydraulic damping. The primary design endeavours to achieve low influence on the flow from the load pressure. This decreases the damping capability of the valve. When using pressure compensators, only the outlet orifice in the directional valve will provide damping to the system [16] [17]. Furthermore, the pump in load sensing systems is controlled in a closed loop control mode, where the highest load is the feedback signal. At certain points of operation, this might result in an oscillatory behaviour. A complete investigation of load sensing systems and their dynamic properties, including pump controllers, can be found in [18]. The dynamics of pressure compensated valves have been studied in, for example, [19] and [20].

A step forward from load sensing systems using conventional spool valves is to decouple the inlet and the outlet orifices in the directional valve. Numerous configurations for individual metering systems have been developed, both in academia as well as in industry [21]. 


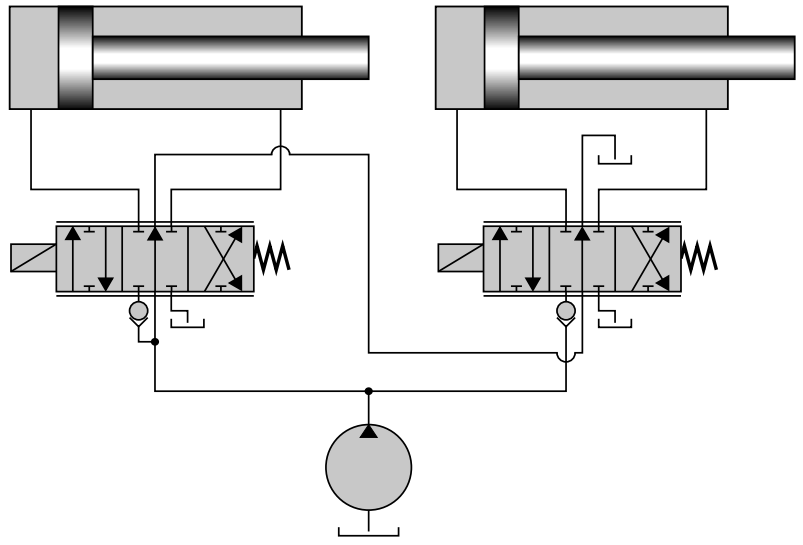

(a) System with open-centre valves and a fixed displacement pump.

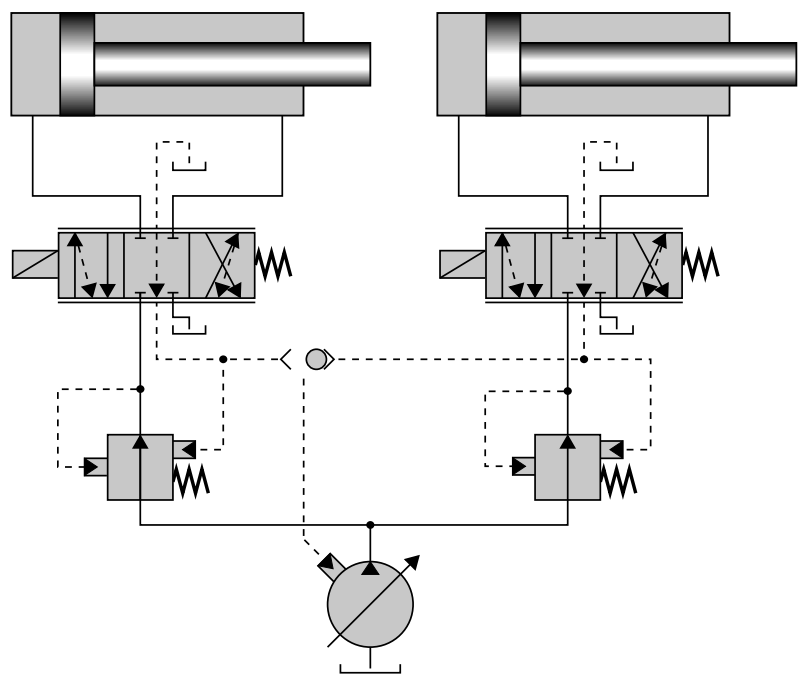

(b) System with pressure compensated load sensing valves and a pressure controlled variable displacement pump.

Figure 1: Different system designs commonly used for the working hydraulics in mobile applications.

These concepts provide a higher degree of freedom as all four orifices are separated and can be controlled individually. The main benefit of this increased freedom is that the flow paths can be changed during operation. Four different operational cases can be identified; normal, regenerative, energy neutral and recuperative [22].

One hot research topic in the area of mobile hydraulics is systems in which the control valves are eliminated along with the metering losses. Multiple concepts have been developed, including pump controlled actuators, hydraulic transformers and electrohydraulic actuators [23]. Such systems are not yet common commercially in mobile applications but can be found in, for example, the aerospace industry [24].

Instead of using one pump to supply all actuators, every actuator has a dedicated pump in pump controlled actuator systems. To control the speed, the pump displacement setting is used as the final control element. All losses are thereby ideally eliminated. In reality, the losses are heavily dependent on the efficiency of the system pumps [23]. These systems can principally be differentiated in two different circuit layouts, either with the pump arranged in a closed circuit [25] [26] or in an open circuit [27].

A hydraulic transformer converts an input flow at a certain pressure level to a different output flow at the expense of a change in pressure level, ideally maintaining the hydraulic power. One way of realizing a transformer is to combine two hydraulic machines, where at least one has a variable displacement. However, the efficiency is limited, mainly because at least one of the machines will operate under partial loading [28]. In recent years, an innovative transformer concept has been developed by the Dutch company Innas BV [29]. The conventional transformer with two hydraulic machines has been replaced by one axial piston unit, thereby avoiding partial loading conditions. A mean efficiency of $93 \%$ in a broad region of op- eration has been reported [30].

The main component in electrohydraulic actuator systems, often referred to as EHA, is a fixed displacement bidirectional hydraulic pump. An electric motor is usually used to power the pump, enabling active control of the rotational speed and thereby the flow to the actuator. A conventional EHA requires a symmetrical actuator in order to ensure flow balance, but solutions for handling asymmetrical cylinders have been proposed [31]. In EHA systems, the pump only operates when control action is needed.

When more than one load is actuated, often only the heaviest load can be operated efficiently in single pump systems. This issue is resolved in valveless systems. When all loads have their own dedicated pump, the pressure can always be matched against the present load. However, one has to bear in mind that valveless systems may require several valves to handle, for example, asymmetric cylinder actuation and meet safety requirements [23] [27].

Furthermore, since all actuators have their own dedicated pump in the valveless concepts, each has to be sized to handle maximum speed. A typical example of a dimensioning motion is the lowering boom motion in a wheel loader. The lowering flow can be several times higher than the maximum pump flow in a similar valve controlled system. The difference is that all flow has to be handled by the pump in valveless system layouts. In single pump systems, the pump can be downsized since not every load is actuated at full speed simultaneously very often. For these reasons, the total installed displacement tends to be high in valveless systems.

When improving energy efficiency in fluid power systems, the trend is to use additional components and more sophisticated control algorithms [32] [33]. Meanwhile, basic constraints such as space requirements, initial cost 
and control complexity are often overlooked. This work investigates how far it is possible to improve traditional load sensing systems by changing the pump controller from a closed loop pressure control mode to an open control mode where the pump displacement setting is controlled based on the sum of all requested load flows. Only one electrically controlled pump and conventional spool valves are needed. Sensors are not required to achieve the desired functionality and all components needed are available on the market [8]. In this work, the system will be referred to as flow control.

\section{The flow control concept}

In mobile hydraulic systems, the actuation of different loads is controlled by joystick signals. These signals pose either a flow or pressure demand from the operator. In applications with high demands on controllability, the signals from the operator often correspond to flow demands. An example is load sensing systems equipped with pressure compensators. Nevertheless, the pump in these kinds of systems is still often pressure controlled.

In systems where the operator's signals correspond to flow demands, it seems more natural to also control the pump by flow. This approach has some benefits regarding energy efficiency, dynamic characteristics and increased flexibility compared to load sensing systems. It also presents some challenges, for example the compensator design.

The idea of flow control is to use the joystick signals to control the pump flow and the valve openings simultaneously. The pump displacement setting is controlled according to the sum of all requested load flows.

When no function is activated, the pump is de-stroked, delivering no flow to the system, and all directional valves are closed. Activating a joystick will simultaneously open

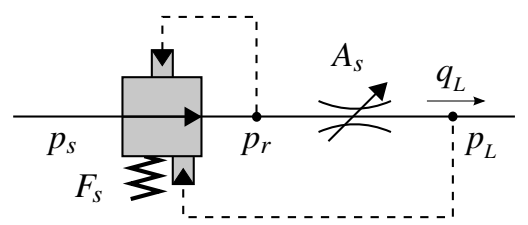

(a) Traditional compensator placed upstream of the directional valve.

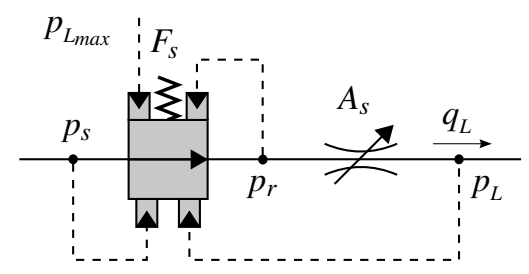

(c) Flow sharing compensator placed upstream of the directional valve. a valve and increase the displacement of the pump. Pressure is built up in the pump hose and when the pump pressure becomes higher than the load pressure there will be a flow to the actuator. When stationary, the flow delivered by the pump will go to the load. The pump pressure will therefore adapt itself to a level needed by the system, resulting in efficiency improvements compared to load sensing systems.

If more than one load is activated, all actuators will suffer from both load interference and load dependency. This can be resolved by introducing sensors to the system. Stenlund [1] and Zähe [2] used the velocities of the actuators as the main feedback signals for pump and valve control. Jongebloed et al. [3] used pressure sensors at all load ports for the valve control. To optimize energy efficiency, the valve at the highest load can be opened to its maximum while lighter loads are controlled by their valve openings.

These controllability issues can also be resolved by using pressure compensators. There will, however, be different demands on the compensator functionality compared to load sensing systems, but it also opens up new possibilities regarding the valve control.

\section{Pressure compensators}

Pressure compensators are commonly used in mobile applications to improve the controllability characteristics. Basically, two different types of compensators can be realized: traditional and flow sharing. Both these types can be realized by placing the compensator either upstream or downstream of the directional valve, see figure 2 .

Traditional compensators control the absolute flow through the directional valve by reducing the pump pressure relative to the load pressure of its own load. This works fine as long as the pump pressure is actively con-

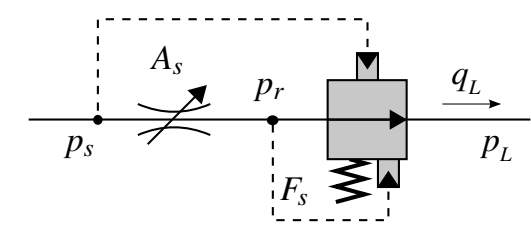

(b) Traditional compensator placed downstream of the directional valve.

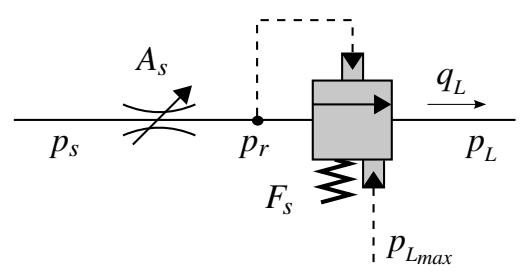

(d) Flow sharing compensator placed downstream of the directional valve.

Figure 2: Four different ways of realizing a pressure compensator. Traditional compensators control the absolute flow through the directional valve while flow sharing compensators distribute the entire pump flow relative to the valve openings. 
trolled, for instance with a load pressure feedback. In case of the pump being saturated, the supply pressure will drop, resulting in the heaviest load losing speed or even stopping.

Flow sharing compensators act as relief valves instead of reducing valves, which means that all functions will be given the same priority. The entire pump flow will thus be distributed relative to the individual valve openings also when the pump is saturated. A pressure controlled pump which has been saturated cannot control the pressure and can therefore be seen as a flow controlled pump. Flow sharing compensators are therefore appropriate to use together with a flow controlled pump.

\section{Pump and valve control approaches}

In flow control systems, the operator's joystick signals control the pump flow and the valve opening simultaneously. For this to work properly, the system software needs knowledge about every flow consumer. However, solutions for attaching auxiliary functions have been proposed [7] [34]. Different control approaches are possible whether traditional or flow sharing compensators are used.

When using traditional pressure compensators, see figure $3 \mathrm{a}$, the absolute flow through the valve is determined by the valve opening. This means that the pump flow has to be matched against the sum of all expected load flows. If this is not the case, two situations may occur.

The pump flow is too low This is the same case as when the pump is saturated in load sensing systems. The compensator spool at the highest load will open completely, resulting in a decrease in speed for that load.

The pump flow is too high Both compensator spools will close more and the pump pressure will increase

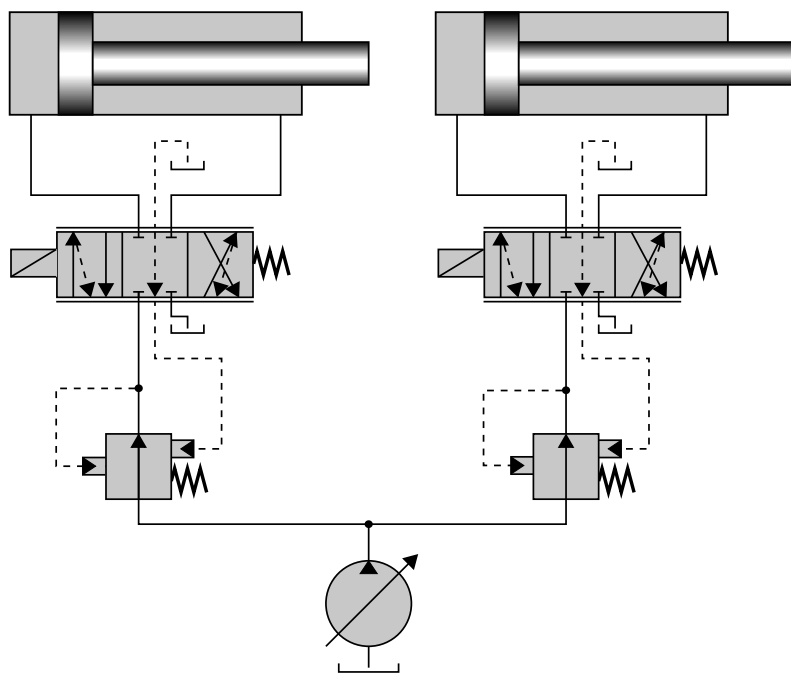

(a) Simplified schematic of a flow control system using traditional compensators. The system can also be realized with traditional compensators placed downstream of the directional valves. until the system relief valve opens. The throttle losses will be huge and the system will emerge as a constant pressure system.

The reason for this is that both the pump and the valves control the absolute flow, resulting in an over-determined flow situation. A lot of research solving this flow matching problem has been presented. Djurovic and Helduser [4] introduced a position sensor placed on the directional valve. This gives precise knowledge of the flow expected by the valve. It is also possible to equip the compensator with a position sensor [5]. If no compensator is close to fully opened, the pump flow is too high. In case of the pump flow being too low, the compensator at the highest load would be completely opened. A bleed-off valve to tank is proposed by several authors [4] [5] [34]. A small overflow is then acceptable, which could be used in closed loop control if a position sensor is added. Fedde and Harms [9] discuss the pros and cons of overflow and underflow when using a bleed-off valve. Grösbrink et al. [35] [36] propose a system design where the pump is pressure controlled for low pump flows and flow controlled for high flow rates. It is also possible to shift from flow control to pressure control in case of an undesirable pressure build-up [37].

There are alternatives to address this flow matching problem without adding additional components or sensors to the system. The key is to implicate the highest load pressure into the compensator and thus get the flow sharing behaviour described in the previous section, see figure $3 \mathrm{~b}$. The entire pump flow will then be distributed relative to all active functions and there will be no flow matching issues. Instead of controlling the flow, the valves will serve as flow dividers. This has been studied in, for example, [8] and [38].

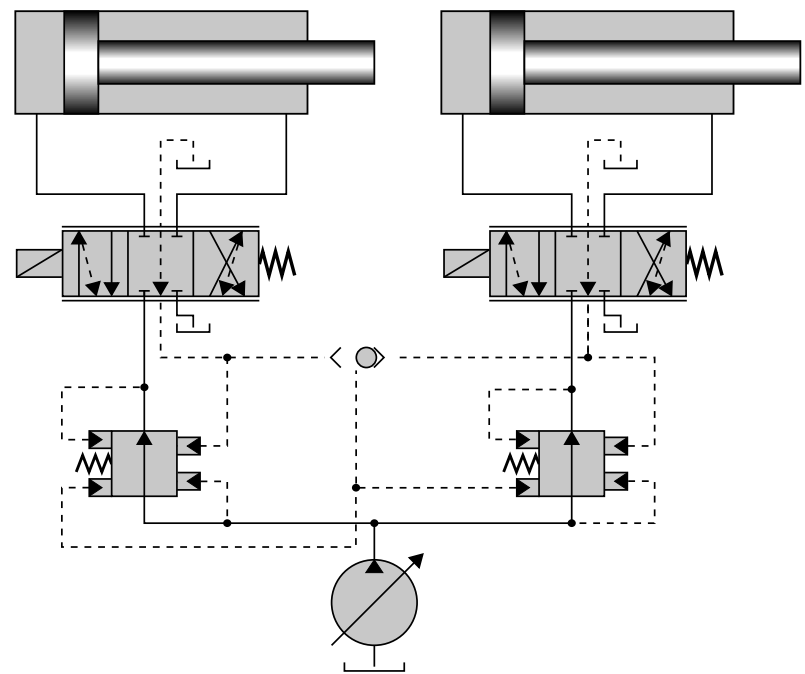

(b) Simplified schematic of a flow control system using flow sharing compensators. The system can also be realized with flow sharing compensators placed downstream of the directional valves.

Figure 3: Two different flow control system designs. The operator joystick signals control the pump displacement setting and the valve openings simultaneously. 
Using a flow controlled pump in combination with flow sharing pressure compensators opens up new possibilities in terms of controlling the directional valves independently of the cylinder velocities [11]. One control approach is to open the valve section at the load with the highest flow demand to its maximum [39] [40]. Other active functions must always be opened in proportion to its flow request. This control approach will minimize the pressure drop across the directional valves and thus save energy.

Another control approach would be to use the valves to increase the system damping. There is an optimal valve opening where the damping is maximized [41]. For example, when a function is oscillating the valve opening could be reduced temporarily in order to dampen the oscillations. When no oscillations are present, a more energy efficient control strategy can be used.

\section{Energy efficiency}

The energy efficiency of flow control systems is similar to that of load sensing systems. The pump pressure is adjusted according to the highest load and high losses might occur when loads with different pressure demands are operated simultaneously. However, instead of a prescribed pressure margin, as in load sensing systems, the pressure drop between pump and load is given by the resistance in the hoses and in the valves. Furthermore, it is also possible to lower the pressure drop across the directional valve by opening the valve at the load with the highest flow demand to its maximum.

In load sensing systems, the pump pressure margin is set to overcome the losses in the pump hose, the compensator and the directional valve. These losses are system dependent and will change with internal and external conditions such as temperature, oil properties, hose length, etc. The pressure margin is set according to the worst case to ensure it is high enough at all operating points.

The pressure drop between pump and load can be divided into three different losses:

Losses between pump and valve There will be a pressure drop between the pump and the valve. The magnitude will depend on the internal and external properties mentioned above, but most importantly the flow rate. A simplified model is that the losses increase with the square of the flow rate.

Losses across the compensator There will be a pressure drop across the compensator. High losses occur if the supply pressure is much higher than the load pressure. This is the case at partial loading conditions. The smallest possible loss occurs when the compensator is fully opened. In that case, the required pressure drop increases with the square of the flow rate.

Losses across the directional valve Typically, the compensator ensures that the pressure drop across the directional valve is constant. However, the smallest possible pressure drop occurs if the valve is fully open. The pressure drop will then follow the flow equation, similar to the compensator pressure drop.

In figure $4 \mathrm{a}$, these three different losses are shown. If the pressure margin is set perfectly, there will be no unnecessary losses at maximum flow rate in load sensing systems. However, at lower flow rates, unnecessary losses will occur. In flow control systems, these losses will be eliminated since the pump pressure is set by the resistance in the hose and the valve.

It is possible to further reduce the losses in flow control systems. This is done by opening the valve section with

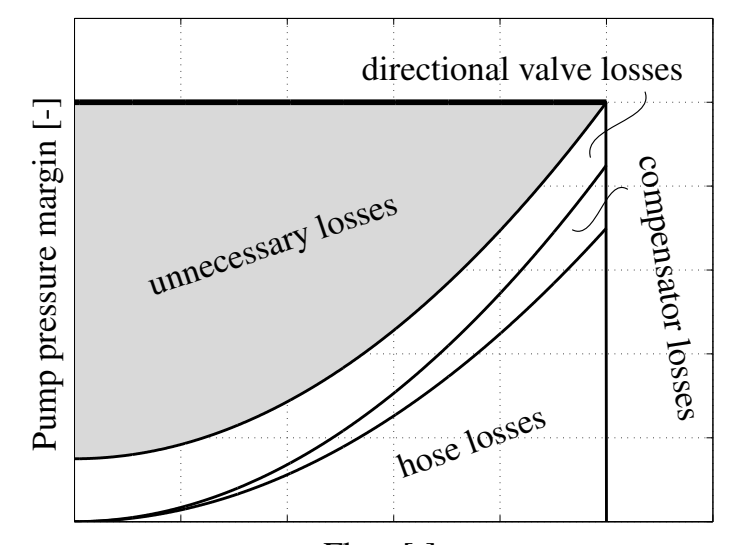

Flow [-]

(a) The pump pressure margin is fixed in load sensing systems and unnecessary losses therefore occur at lower flow rates.

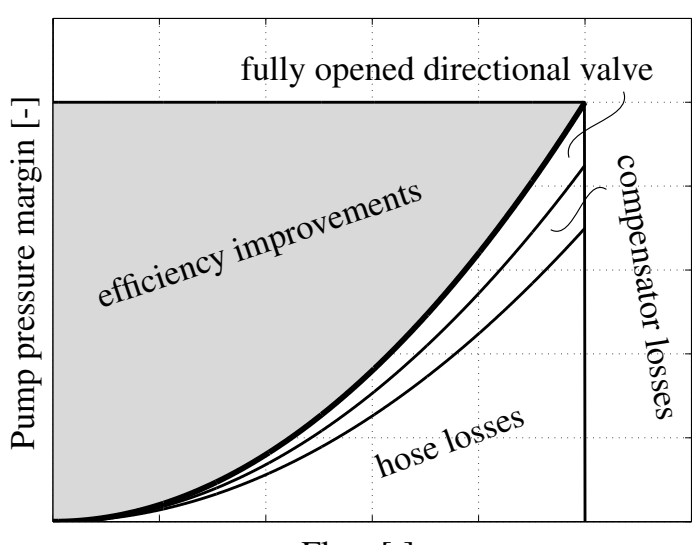

Flow [-]

(b) The pump pressure margin is given by the system resistances in flow control systems. Efficiency improvements are therefore possible.

Figure 4: Classification of the losses between pump and load. Three different losses occur; hose, compensator and directional valve losses. At lower flow rates, unnecessary losses occur in load sensing systems. No unnecessary losses occur in flow control systems. 
the highest flow demand to its maximum, in which case the pressure drop across the directional valve is minimized and additional energy savings are possible, see figure $4 \mathrm{~b}$.

A flow control system without pressure compensators would increase the efficiency even further. In that case, the valve section at the highest load might be opened completely. However, its functionality requires closed loop control and is therefore sensor dependent [3].

As can be seen in figure 4, the two system layouts have the same efficiency at maximum flow rate if the pump pressure margin is set perfectly in the load sensing system. Flow control systems have higher efficiency for smaller flow rates. However, it is important to consider the power losses rather than the pressure losses. For low flow rates, the power loss will be small even for high pressure drops. Figure 5 shows the power saving opportunities for flow control systems. The largest power savings occur in the medium flow rate area. If the directional valve is opened completely, even more power can be saved.

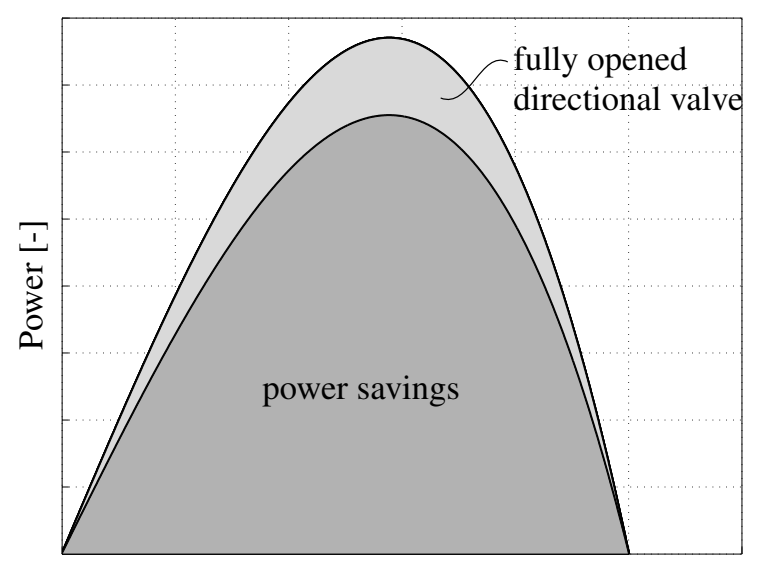

Flow [-]

Figure 5: Power savings in flow control systems compared to load sensing systems. More power can be saved if the directional valve is completely opened. No power is saved at maximum flow rate if the pressure margin is set perfectly in load sensing systems.

Flow control systems have no unnecessary losses for the highest load. All losses that occur are necessary and limited by, for example, the diameter of the hoses and the maximum opening areas in the valve. However, flow control systems still have high losses under partial loading conditions. To increase efficiency even further, individual metering valves or additional hydraulic machines are required.

A flow control system with two hydraulic pumps has been studied in [42] and [43]. The aim is to reduce the losses under partial loading conditions without increasing the total installed displacement. This is achieved by connecting the two pumps when high flow rates are required by one load. Connecting several pumps at high flow rates is a common solution for more simple systems, for example, in excavators.

\section{Dynamic characteristics}

The only difference between load sensing and flow control is the absence of the feedback to the pump controller in flow control systems. Nevertheless, there are fundamental dynamic differences between the two system layouts.

The dynamic behaviour of load sensing systems can be described by equations (1)-(4) [44]. By reducing the block diagram in figure $6 \mathrm{a}$, the open loop transfer function from desired pump pressure margin $\Delta P_{p_{\text {ref }}}$ to actual pressure difference $\Delta P_{p}=P_{p}-P_{L}$ can be derived according to equation (5).

$$
\begin{aligned}
& G_{p}=\frac{Q_{p}}{\Delta P_{p_{r e f}}-\Delta P_{p}}=\frac{1}{L_{p} s} \\
& H_{s}=\frac{P_{p}}{Q_{p}-Q_{L}}=\frac{1}{C_{p} s} \\
& G_{v}=\frac{Q_{L}}{P_{p}-P_{L}}=K_{c} \\
& Z_{L}=\frac{P_{L}}{Q_{L}}=\frac{m_{L} s+B_{p}}{C_{L} m_{L} s^{2}+C_{L} B_{p} s+A_{c}^{2}} \\
& G_{p} G_{o}=G_{p} \frac{H_{s}}{1+G_{v}\left(Z_{L}+H_{s}\right)}
\end{aligned}
$$

By closing the control loop, the pump controller, $G_{p}$, is a part of the loop gain, $G_{p} G_{o}$, as shown in figure $6 \mathrm{~b}$. To achieve a stable system the loop gain must be kept lower than unity when the phase crosses $-180^{\circ}$. On the other hand, it would be feasible to increase the gain of the pump and its controller to achieve a system that meets the response requirements. To achieve a system, with the desired response, the gain of the pump controller is increased, but at the same time the system is approaching its stability limit. One should bear in mind that stability at one operational point will not guarantee stability at another, see figure 7 .

Table 1: Parameter values used in figure 7.

\begin{tabular}{lrl}
\hline Parameter & Value & Unity \\
\hline$A_{c}$ & 0.005 & $\mathrm{~m}^{2}$ \\
$B_{p}$ & 10000 & $\mathrm{Ns} / \mathrm{m}$ \\
$C_{L}$ & $4 \cdot 10^{-12}$ & $\mathrm{~m}^{3} / P a$ \\
$C_{p}$ & $5 \cdot 10^{-12}$ & $\mathrm{~m}^{3} / P a$ \\
$K_{c}$ & $1 \cdot 10^{-9}$ & $\mathrm{~m}^{5} / \mathrm{Ns}$ \\
$L_{p}$ & $5 \cdot 10^{8}$ & $\mathrm{~Pa} \mathrm{~s} / \mathrm{m}^{3}$ \\
$m_{L}$ & {$[60001200030000]$} & $\mathrm{kg}$ \\
\hline
\end{tabular}

The dynamic behaviour of flow control systems can be described by almost the same set of equations, (1)-(4). The only difference is the absence of the feedback to the pump controller, see figure 8 . This results in a fundamental dynamic difference between load sensing systems and flow control systems. Since there is no closed loop for the pump controller, the stability issues described above are eliminated. The pump and its controller can thereby be designed to meet the response requirements without considering system stability. This has been verified by experiments in [8] and [38]. 


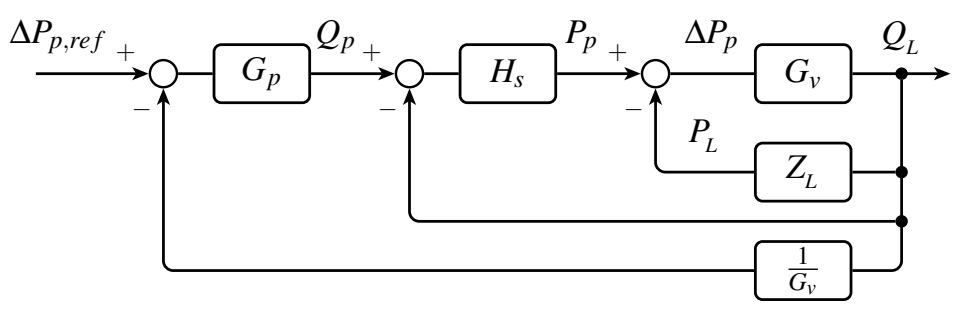

(a) Block diagram of a load sensing system derived from equations (1)-(4).

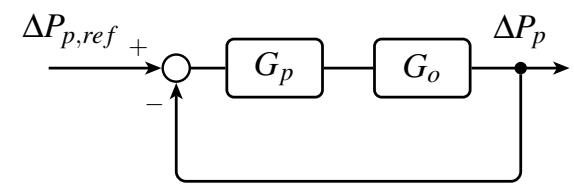

(b) Rearranged block diagram with the loop gain $G_{p} G_{o}$.

Figure 6: Linear model of a load sensing system.

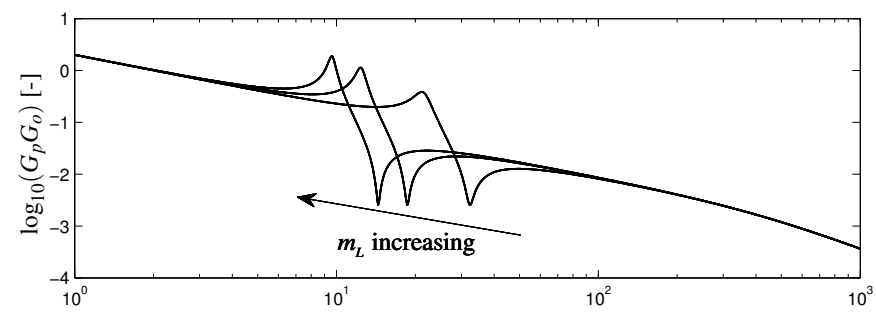

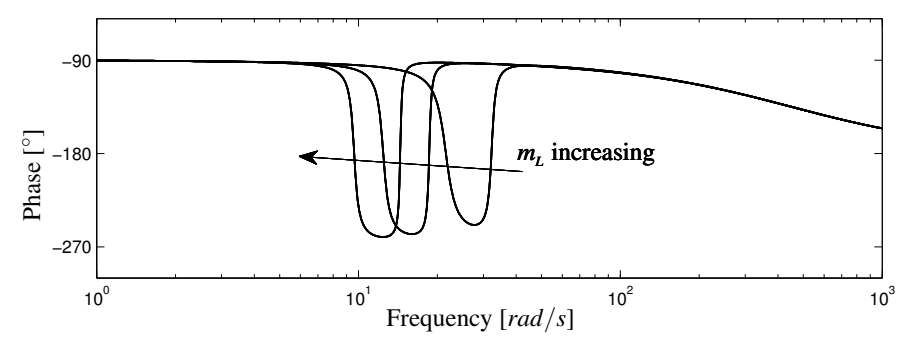

(a) Bode plot of the open loop gain in figure $6 \mathrm{~b}, G_{p} G_{o}$.

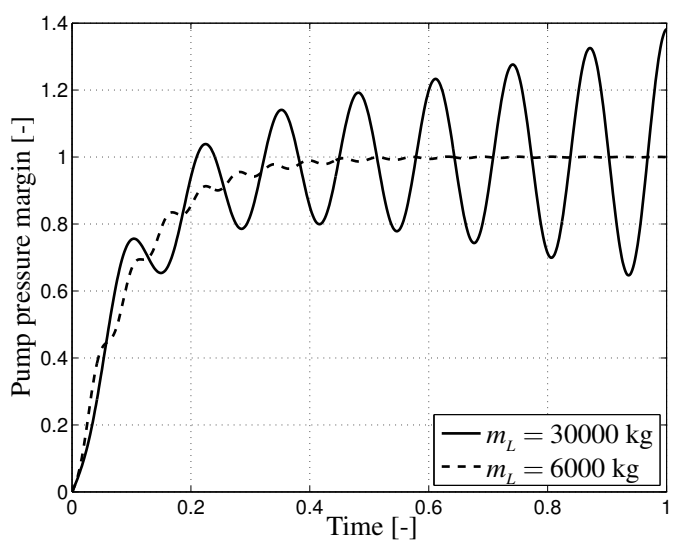

(b) Step response of the closed loop gain in figure $6 \mathrm{~b}, G_{p} G_{o}$.

Figure 7: Dynamic characteristics of load sensing systems. The parameter values are shown in table 1. At specific points of operation, load sensing systems may become unstable. Flow control systems have no such stability issues due to the absence of the feedback to the pump controller.

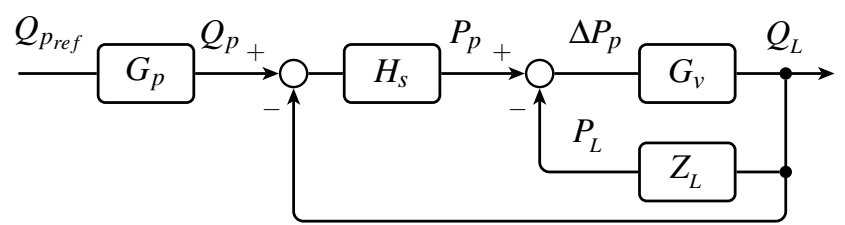

(a) Block diagram of a flow control system derived from equations (1)-(4).

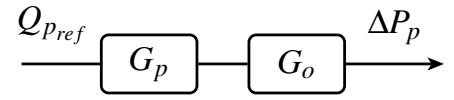

(b) Rearranged block diagram with no feedback present.

Figure 8: Linear model of a flow control system. 


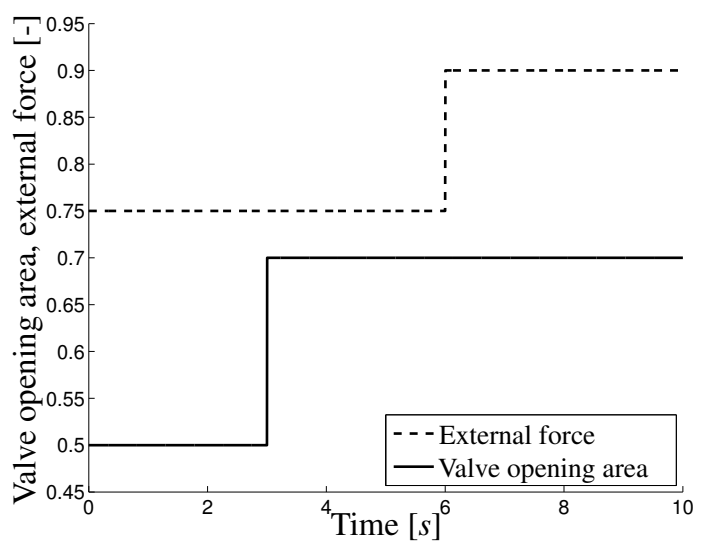

(a) A step is made in the valve opening area after 3 seconds and in the external force after 6 seconds.

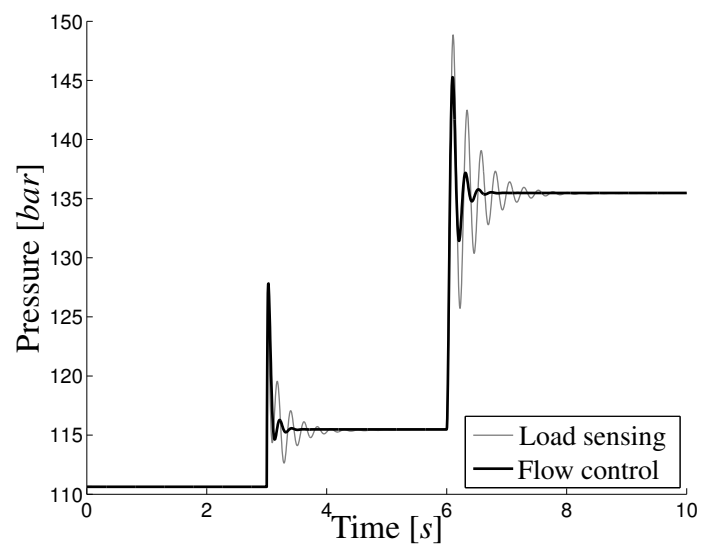

(c) Cylinder pressures as a function of time.

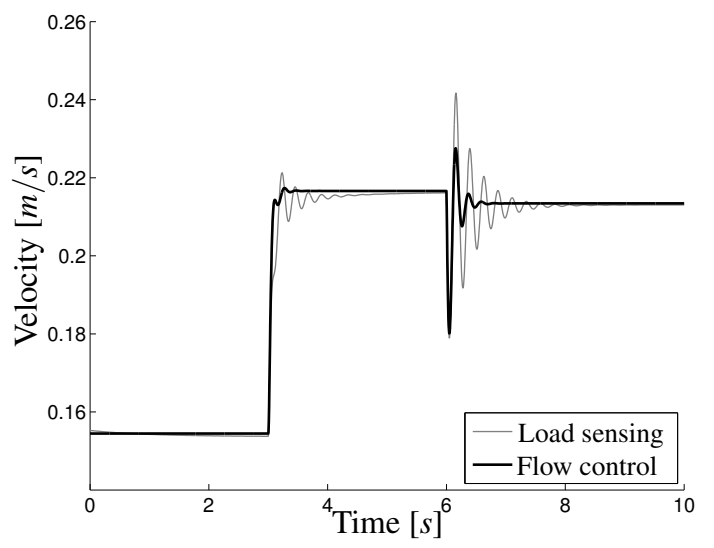

(b) Cylinder velocities as a function of time.

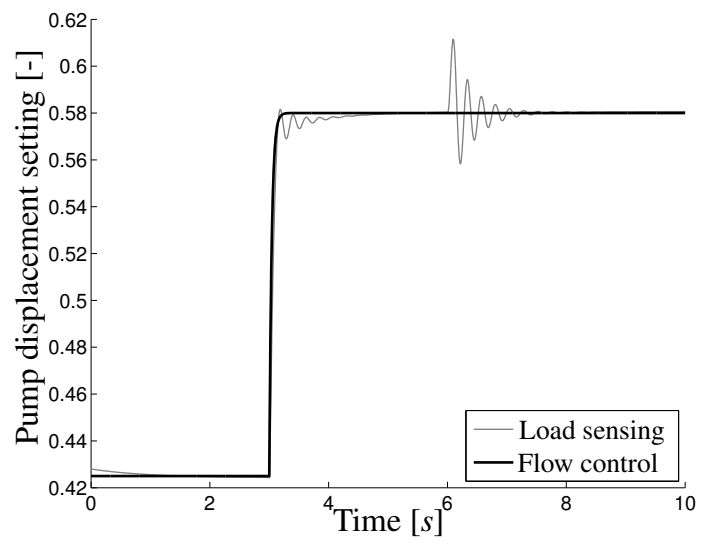

(d) Pump displacement settings as a function of time.

Figure 9: Simulation results of a load sensing system model and a flow control system model. The load sensing system model is more oscillative due to its closed loop pressure control.

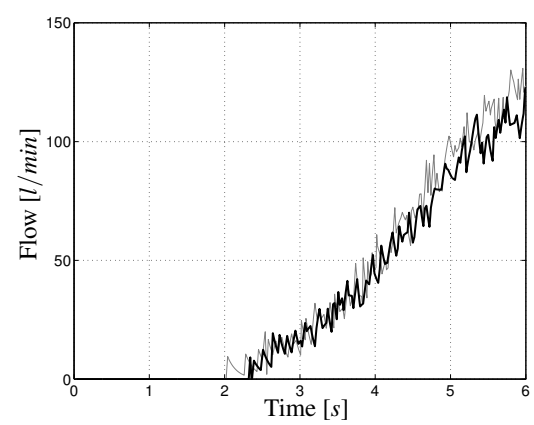

(a) Measured flow for both systems. The flow is increased from zero to maximum.

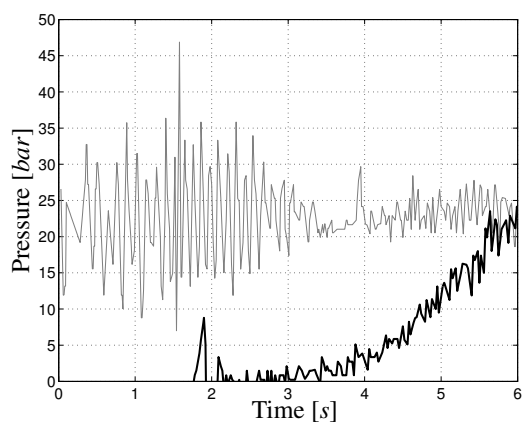

(b) Measured pump pressure margin for both systems while the flow is increased.

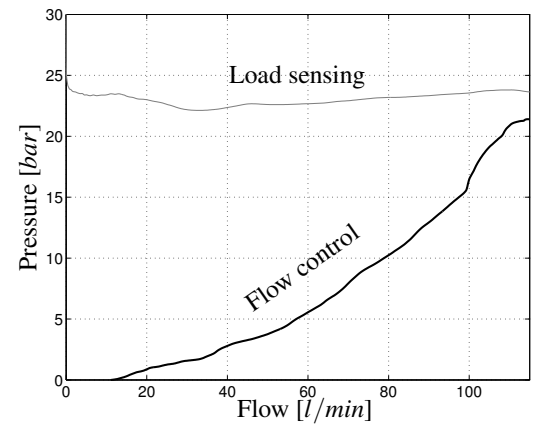

(c) Measured pump pressure margin as a function of measured flow. Load sensing systems have a constant margin while flow control systems have a margin given by the system resistances.

Figure 10: Experimental results showing the potential of reducing the pump pressure margin in flow control systems compared to load sensing systems. 


\section{Simulation results}

A nonlinear simulation model has been built in Hopsan [45] [46] to illustrate some of the differences between load sensing and flow control. The model consists of a pump, a directional valve and a cylinder load. A step is made in the valve opening area and also in the external force according to figure 9 . The load sensing system model is more oscillative in both cases. It can also be noted that the pump displacement setting for the load sensing system is oscillating when a step is made in the external force, although the velocity should remain constant.

\section{Experimental results}

To verify the energy efficiency improvements in the flow control concept, measurements were performed on a wheel loader application with an operational weight of $6900 \mathrm{~kg}$. The machine was equipped with a pump that can be operated in both pressure and flow control modes and a valve prepared for use with both traditional and flow sharing compensators, placed upstream of the directional valve.

In figure 10c, the pump pressure margin for both the load sensing and the flow control system can be seen. The measurements agree with the theoretical pressure margin shown in figure $4 \mathrm{~b}$. The flow sent by the pump is similar in both systems, see figure 10a. It can also be observed in figure $10 \mathrm{~b}$ that the pressure is more oscillative in the load sensing system. This is because the pump controller operates in a closed loop control mode [18].

A short loading cycle [47] has also been performed to compare load sensing and flow control. Only the working hydraulics have been taken into consideration, neither the steering nor the transmission. For this particular application, the energy consumption was reduced by $14 \%$ for the flow control system [40]. This is the same order of magnitude as in experiments performed in [34] and [38].

\section{Conclusions}

A system design where the pump displacement setting is controlled based on the operator's command signals rather than maintaining a certain pressure margin above the highest load pressure has been studied in this article. The fundamental difference between flow control and load sensing is that the load pressure feedback hose to the pump controller can be removed. Instead of controlling the pump in a closed loop control mode, an open control mode can be used with no feedback present. This makes the system design process simpler since the pump can be designed to meet the response requirements without considering system stability. As long as the pump is stable as an isolated component, it will not cause any stability issues in the complete system. In load sensing systems on the other hand, an apparently stable pump can cause instability in the complete system.

Flow control systems are more energy efficient com- pared to load sensing systems. This is because the pressure difference between pump and load is given by the system resistance rather than a prescribed pump pressure margin. The two system layouts have the same efficiency when the pump is saturated. However, at all other operational points, flow control systems have higher energy efficiency than load sensing systems. There are also potential energy savings tied to the absence of active control of the pump.

It is possible to combine flow control with other working hydraulic systems. For example, flow control could be used as a complement to pump controlled actuators. Some high power consumers could have one dedicated pump while other, low power, consumers share one common pump. In that case, the total installed displacement could be kept at a reasonable level while all pumps could be displacement controlled. Another possibility might be to use an electric motor in combination with a fixed displacement pump, like in EHA systems, but share it with several loads.

\section{Funding}

This research was supported by Parker Hannifin, Borås, Sweden.

\section{References}

[1] S. Stenlund. Electrohydraulic guide system, patent, EP 0417087, 1988.

[2] B. Zähe. Energiesparende Schaltungen hydraulischer Antriebe mit veränderlichem Versorgungsdruck und ihre Regelung. $\mathrm{PhD}$ thesis, RheinischWestfaaalische Technische Hochschule Aachen, 1993.

[3] H. Jongebloed, D. van Büren, U. Völkel, and C. Jabs. Energy-saving valve system for mobile applications - load-control-system (LCS). In 4th International Fluid Power Conference (IFK), pages 117128, Dresden, Germany, 2004.

[4] M. Djurovic and S. Helduser. New control strategies for electrohydraulic load-sensing. In Fluid Power and Motion Control (FPMC), pages 201-210, Bath, UK, 2004.

[5] M. Djurovic, S. Helduser, and G. Keuper. Neue lösungen zum elektrohydraulischen load-sensing. In 4th International Fluid Power Conference (IFK), volume 2, pages 59-70, Dresden, Germany, 2004.

[6] M. Djurovic. Energiesparende Antriebssysteme für die Arbeitshydraulik mobiler Arbeitsmaschinen "Elektrohydraulisches Flow Matching". PhD thesis, Institut für Fluidtechnik der Technischen Universität Dresden, 2007.

[7] B. Eriksson and J.-O. Palmberg. How to handle auxiliary functions in energy efficient, single pump, flow 
sharing mobile systems. In The 7th International Fluid Power Conference (IFK), Aachen, Germany, 2010.

[8] C. Latour. Electrohydraulic flow matching (EFM) - the next generation of load sensing controls. In Mobile, 2006.

[9] T. Fedde and H.-H. Harms. An adaptive hydraulic system for mobile applications. In The 5th International Fluid Power Conference (IFK), volume 3, pages 95-106, Aachen, Germany, 2006.

[10] R. Finzel. Elektrohydraulische Steuerungssysteme für mobile Arbeitsmaschinen. $\mathrm{PhD}$ thesis, Institut für Fluidtechnik der Technischen Universität Dresden, 2010 .

[11] M. Axin. Fluid Power Systems for Mobile Applications - with a Focus on Energy Efficiency and Dynamic Characteristics. Licentiate thesis, Linköping University, 2013.

[12] M. Scherer, M. Geimer, and B. Weiss. Contribution on control strategies of flow-on-demand hydraulic circiuts. In The 13th Scandinavian International Conference on Fluid Power (SICFP2013), Linköping, Sweden, 2013.

[13] G. Palmgren. On Secondary Controlled Hydraulic Systems. Licentiate thesis, Linköping University, 1988.

[14] P. Dengler, M. Geimer, H. Baum, G. Schuster, and C. Wessing. Efficiency improvement of a constant pressure system using an intermediate pressure line. In 8th International Fluid Power Conference (IFK), volume 1, pages 567-578, Dresden, Germany, 2012.

[15] B.R. Andersson. A survey of load-sensing systems. The BFPR Journal, 13:103-115, 1980.

[16] M. Axin, J.-O. Palmberg, and P. Krus. Optimized damping in cylinder drives using the meterout orifice - design and experimental verification. In 8th International Fluid Power Conference (IFK), volume 1, pages 579-591, Dresden, Germany, 2012.

[17] M. Axin and P. Krus. Design rules for high damping in mobile hydraulic systems. In The 13th Scandinavian International Conference on Fluid Power (SICFP2013), Linköping, Sweden, 2013.

[18] P. Krus. On Load Sensing Fluid Power Systems With Special Reference to Dynamic Properties and Control Aspects. PhD thesis, Linköping University, 1988.

[19] H. Pettersson, P. Krus, A. Jansson, and J.-O. Palmberg. The design of pressure compensators for load sensing hydraulic systems. In UKACC International Conference on Control'96, 1996.
[20] D. Wu, R. Burton, G. Schoenau, and D. Bitner. Analysis of a pressure-compensated flow control valve. Journal of Dynamic Systems, Measurement, and Control, 129:203-211, 2007.

[21] B. Eriksson and J.-O. Palmberg. Individual metering fluid power systems: Challenges and opportunities. Proceedings of the Institution of Mechanical Engineers, Part I: Journal of Systems and Control Engineering, 225:196-211, 2011.

[22] B. Eriksson. Mobile Fluid Power Systems Design - with a Focus on Energy Efficiency. PhD thesis, Linköping University, 2010.

[23] C. Williamson and M. Ivantysynova. The effect of pump efficiency on displacement-controlled actuator systems. In The Tenth Scandinavian International Conference on Fluid Power (SICFP'07), Tampere, Finland, 2007.

[24] E.T. Raymond and C.C. Chenoweth. Aircraft Flight Control Actuation System Design. Society of Automotive Engineers, 1993.

[25] R. Rahmfeld and M. Ivantysynova. Displacement controlled linear actuator with differential cylinder a way to save primary energy in mobile machines. In Fifth International Conference on Fluid Power Transmission and Control (ICFP), volume 1, pages 316-322, Hangzhou, China, 2001.

[26] R. Rahmfeld, M. Ivantysynova, and J. Weber. Displacement controlled wheel loader - a simple and clever solution. In 4th International Fluid Power Conference (IFK), volume 2, pages 183-196, Dresden, Germany, 2004.

[27] K. Heybroek. Saving Energy in Construction Machinery using Displacement Control Hydraulics Concept Realization and Validation. Licentiate thesis, Linköping University, 2008.

[28] R. Werndin and J.-O. Palmberg. Hydraulic transformers - comparison of different designs. In The Eighth Scandinavian International Conference of Fluid Power (SICFP'03), Tampere, Finland, 2003.

[29] P. Achten, Z. Fu, and G. Vael. Transforming future hydraulics: a new design of a hydraulic transformer. In The 5th Scandinavian International Conference on Fluid Power (SICFP'97), Linköping, Sweden, 1997.

[30] P. Achten, G. Vael, T. van den Brink, J. Potma, and M. Schellekens. Efficiency measurements of the hydrid motor/pump. In The Twelfth Scandinavian International Conference on Fluid Power (SICFP'11), volume 3, pages 41-49, Tampere, Finland, 2011.

[31] R. Gomm and D. Vanderlaan. Velocity control of unbalanced hydraulic actuator subjected to over-center load conditions, patent, EP 2318720, 2009. 
[32] J. Weber and W. Burget. Mobile systems - markets, industrial needs and technological trends. In 8th International Fluid Power Conference (IFK), volume 2, pages 23-54, Dresden, Germany, 2012.

[33] B. Eriksson. Control Strategy for Energy Efficient Fluid Power Actuators - Utilizing Individual Metering. Licentiate thesis, Linköping University, 2007.

[34] K. Mettälä, M. Djurovic, G. Keuper, and P. Stachnik. Intelligent oil flow management with EFM: The potentials of electrohydraulic flow matching in tractor hydraulics. In The Tenth Scandinavian International Conference on Fluid Power (SICFP'07), volume 3, pages 25-34, Tampere, Finland, 2007.

[35] B. Grösbrink and H.-H. Harms. Control concept for an advanced load-sensing system. In 7th International Conference on Fluid Power Transmission and Control, Hangzhou, China, 2009.

[36] B. Grösbrink, T. von Baumgarten, and H.-H. Harms. Alternating pump control for a load-sensing system. In 7th International Fluid Power Conference (IFK), Aachen, Germany, 2010.

[37] B. Xu, W. Liu, M. Cheng, and H. Yang. A new electrohydraulic load sensing control system for hydraulic excavators. In 8th International Fluid Power Conference (IFK), volume 1, pages 553-565, Dresden, Germany, 2012.

[38] R. Finzel and S. Helduser. Energy-efficient electrohydraulic control systems for mobile machinery / flow matching. In 6th International Fluid Power Conference, volume 1, pages 89-102, Dresden, Germany, 2008.

[39] R. Finzel and S. Helduser. New electro-hydraulic control systems for mobile machinery. In Fluid Power and Motion Control (FPMC), pages 309-321, Bath, UK, 2008.

[40] M. Axin, B. Eriksson, and J.-O. Palmberg. Energy efficient load adapting system without load sensing design and evaluation. In The 11th Scandinavian International Conference on Fluid Power (SICFP'09), Linköping, Sweden, June 2009.

[41] M. Axin, B. Eriksson, J.-O. Palmberg, and P. Krus. Dynamic analysis of single pump, flow controlled mobile systems. In The Twelfth Scandinavian International Conference on Fluid Power (SICFP'11), volume 2, pages 223-238, Tampere, Finland, May 2011.

[42] R. Finzel, S. Helduser, and D.-S. Jang. Electrohydraulic control systems for mobile machinery with low energy consumption. In Proceedings of the Seventh International Conference on Fluid Power Transmission and Control (ICFP), pages 214-219, Hangzhou, China, 2009.
[43] R. Finzel, S. Helduser, and D.-S. Jang. Hydraulic dual-circuit system to improve the energy efficiency of mobile machines. In 7th International Fluid Power Conference (IFK), Aachen, Germany, 2010.

[44] H.E. Merritt. Hydraulic Control Systems. John Wiley \& Sons, Inc., 1967.

[45] M. Axin, R. Braun, A. Dell'Amico, B. Eriksson, P. Nordin, K. Pettersson, I. Staack, and P. Krus. Next generation simulation software using transmission line elements. In Fluid Power and Motion Control (FPMC), pages 265-276, Bath, UK, September 2010.

[46] B. Eriksson, P. Nordin, and P. Krus. Hopsan NG, a $\mathrm{C}++$ implementation using the TLM simulation technique. In The 51st Conference on Simulation and Modelling (SIMS), 2010.

[47] R. Filla. Quantifying Operability of Working Machines. PhD thesis, Linköping University, 2011.

\section{Nomenclature}

The quantities used in this paper are listed in the table. Capital letters are used for linearized and Laplace transformed variables.

\begin{tabular}{lll}
\hline Quantity & Description & Unity \\
\hline$A_{c}$ & Cylinder area & $\mathrm{m}^{2}$ \\
$A_{s}$ & Directional valve opening area & $\mathrm{m}^{2}$ \\
$B_{p}$ & Viscous friction coefficient & $\mathrm{Ns} / \mathrm{m}$ \\
$C_{L}$ & Capacitance of the load & $\mathrm{m}^{3} / \mathrm{Pa}$ \\
& cylinder & \\
$C_{p}$ & Capacitance of the pump hose & $\mathrm{m}^{3} / \mathrm{Pa}$ \\
$F_{S}$ & Compensator spring stiffness & $\mathrm{N}$ \\
$K_{C}$ & Flow-pressure coefficient for & $\mathrm{m}^{3} / \mathrm{Pa} \mathrm{s}$ \\
& the valve & \\
$L_{p}$ & Pump inductance & $\mathrm{Pa} \mathrm{s} / \mathrm{m}^{3}$ \\
$m_{L}$ & Load mass & $\mathrm{kg}$ \\
$p_{L}$ & Load pressure & $\mathrm{Pa}$ \\
$P_{L}$ & Load pressure & $\mathrm{Pa}$ \\
$p_{L_{m a x}}$ & Maximum load pressure & $\mathrm{Pa}$ \\
$P_{p}$ & Pump pressure & $\mathrm{Pa}$ \\
$p_{r}$ & Reduced pressure & $\mathrm{Pa}$ \\
$p_{s}$ & Supply pressure & $\mathrm{Pa}$ \\
$q_{L}$ & Load flow & $\mathrm{m} 3 / \mathrm{s}$ \\
$Q_{L}$ & Load flow & $\mathrm{m} 3 / \mathrm{s}$ \\
$Q_{p}$ & Pump flow & $\mathrm{m} 3 / \mathrm{s}$ \\
$s$ & Laplace variable & $1 / \mathrm{s}$ \\
$\Delta P_{p}$ & Pump pressure margin & $\mathrm{Pa}$ \\
$\Delta P_{p_{r e f}}$ & Pump pressure margin demand & $\mathrm{Pa}$ \\
$G_{o}$ & Open loop transfer function & \\
$G_{p}$ & Pump transfer function & \\
$G_{v}$ & Valve transfer function & \\
$H_{s}$ & Pump hose transfer function & \\
$Z_{L}$ & Load transfer function & \\
\hline & & \\
& & \\
& & \\
& & \\
& &
\end{tabular}

